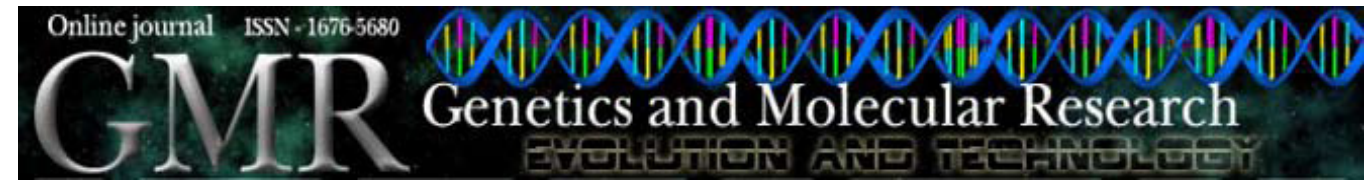

\title{
Genetic diversity of turmeric germplasm (Curcuma longa; Zingiberaceae) identified by microsatellite markers
}

\author{
M.S. Sigrist ${ }^{1}$, J.B. Pinheiro ${ }^{1}$, J.A. Azevedo Filho ${ }^{2}$ and M.I. Zucchi ${ }^{3}$ \\ ${ }^{1}$ Departamento de Genética, Universidade de São Paulo (ESALQ), \\ Piracicaba, SP, Brasil \\ ${ }^{2}$ Polo APTA, Regional Leste Paulista, Monte Alegre do Sul, SP, Brasil \\ ${ }^{3}$ Agência Paulista de Tecnologia dos Agronegócios, Piracicaba, SP, Brasil \\ Corresponding author: M.I. Zucchi \\ E-mail: mizucchi@apta.sp.gov.br
}

Genet. Mol. Res. 10 (1): 419-428 (2011)

Received September 1, 2010

Accepted January 19, 2011

Published March 9, 2011

DOI 10.4238/vol10-1gmr1047

\begin{abstract}
Turmeric (Curcuma longa) is a triploid, vegetatively propagated crop introduced early during the colonization of Brazil. Turmeric rhizomes are ground into a powder used as a natural dye in the food industry, although recent research suggests a greater potential for the development of drugs and cosmetics. In Brazil, little is known about the genetic variability available for crop improvement. We examined the genetic diversity among turmeric accessions from a Brazilian germplasm collection comprising 39 accessions collected from the States of Goiás, Mato Grosso do Sul, Minas Gerais, São Paulo, and Pará. For comparison, 18 additional genotypes were analyzed, including samples from India and Puerto Rico. Total DNA was extracted from lyophilized leaf tissue and genetic analysis was performed using 17 microsatellite markers (single-sequence repeats). Shannon-Weiner indexes ranged from 0.017 (Minas Gerais) to 0.316 (São Paulo). Analyses of molecular variance (AMOVA) demonstrated
\end{abstract}


major differences between countries (63.4\%) and that most of the genetic diversity in Brazil is found within states (75.3\%). Genotypes from São Paulo State were the most divergent and potentially useful for crop improvement. Structure analysis indicated two main groups of accessions. These results can help target future collecting efforts for introduction of new materials needed to develop more productive and better adapted cultivars.

Key words: Curcuma longa L.; Natural dye; Genetic resources; Genetic divergence; SSR markers

\section{INTRODUCTION}

Turmeric (Curcuma longa L.) is a tropical perennial herb belonging to the family Zingiberacea. Commonly used as a spice and natural food dye, turmeric powder is obtained from C. longa rhizomes, which, after drying and processing, result in a bright yellow powder valued as a natural food dye. The use of natural dyes by the food industry has increased recently, in part due to laws restricting the use of artificial food colorants in many countries (Antunes and Araújo, 2000; Cecílio-Filho et al., 2000). Consequently, turmeric has become an important ingredient in a variety of industrialized products such as sauces, mustards, dry seasonings, baking mixes, processed cheese, dry soups, beverages, and confections (Sasikumar, 2005). In addition, turmeric also has a variety of pharmacological activities, with recent studies finding that curcumin, the yellow color pigment of turmeric, is a powerful antioxidant, anti-parasitic, antispasmodic and anti-inflammatory compound, which may also inhibit carcinogenesis (Araújo and Leon, 2001; Ravindran et al., 2007).

Because of its increasing demand in both the food and pharmaceutical industries, turmeric growing techniques have been the focus of several studies (Meenakshi and Sulikeri, 2003; May et al., 2005). However, to obtain further increases in productivity, information regarding the crop's genetic diversity is needed for breeding programs (Nass, 2001).

Turmeric is a cross-pollinated, triploid species $(2 n=3 x=63)$, which can be vegetatively propagated using its underground rhizomes (Sasikumar, 2005). Since hybridization is ineffective in most cases, genetic improvement is often limited to germplasm selection and mutation breeding (Ravindran et al., 2007). Viable seed set can be obtained under certain conditions, which enables recombination breeding through hybridization and open-pollinated progeny selection (Sasikumar, 2005). Examples of varieties obtained from open-pollinated seedling selections are the cultivars 'Prabha' and 'Prathibha' (Sasikumar et al., 1996).

Even though germplasm collections represent the main source of variability for turmeric genetic improvement, studies aimed at characterizing these collections are scarce and mostly restricted to the phenotypic evaluation of accessions from India, which is the major turmeric grower of the world (Chandra et al., 1997; Lynrah et al., 1998; Singh et al., 2003; Chaudhary et al., 2006). However, the use of phenotypic traits in germplasm characterization may be limited due to the small number of descriptors available and the 
influence of environment and genotype x environment interactions (Ferreira et al., 2007). Therefore, Pinheiro et al. (2003) attempted to use random amplified polymorphic DNA (RAPD) markers to screen 20 turmeric accessions from Brazil, providing useful insights into the structure of genetic diversity. However, RAPD markers are known to yield low levels of polymorphism when compared to other molecular markers, such as microsatellites (simple sequence repeats, SSR) (Powell et al., 1996).

Since knowledge of the genetic variation in the turmeric germplasm is essential to increase the efficiency of selection in breeding programs, as well as to direct conservation strategies in germplasm collections, the present study genetically characterized a Brazilian germplasm collection of turmeric using SSR markers.

\section{MATERIAL AND METHODS}

Curcuma longa genotypes were obtained from a collection maintained by the Department of Genetics of the University of São Paulo (ESALQ, USP). The collection comprises 39 accessions collected from different locations in Brazil (Table 1). In addition to these accessions, 18 other genotypes were analyzed for further comparison, including turmeric DNA samples from Brazil, India and Puerto Rico and one accession of common ginger (Zingiber officinale Roscoe).

Genomic DNA was extracted from lyophilized leaf tissue from each genotype using the CTAB method (Doyle and Doyle, 1987). DNA quantification was made using a $\lambda$-uncut marker and banding patterns were visualized under UV light, after electrophoresis on a $1 \%(\mathrm{w} / \mathrm{v})$ agarose gel containing $0.1 \mu \mathrm{g} / \mathrm{mL}$ ethidium bromide. Genetic analysis was performed using 17 microsatellite markers described by Sigrist et al. (2009). Polymerase chain reaction (PCR) was performed using $2 \mu \mathrm{L}$ template DNA $(10 \mathrm{ng} / \mu \mathrm{L}), 2 \mu \mathrm{L}$ of the forward and reverse primers $(10 \mu \mathrm{M}$ each $), 1 \mu \mathrm{L}$ dNTP $(2.5 \mathrm{mM}), 1.5 \mu \mathrm{L}$ buffer solution ( $50 \mathrm{mM} \mathrm{KCl} / 10 \mathrm{mM}$ Tris-HCl, $\mathrm{pH} 8.9), 0.9 \mu \mathrm{L} \mathrm{MgCl}_{2}(50 \mathrm{mM}), 1 \mathrm{U}$ Taq DNA polymerase and $6.6 \mu \mathrm{L}$ Milli-Q water. PCR running conditions were: $5 \mathrm{~min}$ at $94^{\circ} \mathrm{C}$, followed by 35 cycles of $94^{\circ} \mathrm{C}$ for $1 \mathrm{~min}$, specific annealing temperature according to the primer pair for $1 \mathrm{~min}$ and $72^{\circ} \mathrm{C}$ for $1 \mathrm{~min}$, finishing by $72^{\circ} \mathrm{C}$ for $30 \mathrm{~min}$. PCR products were then visualized by electrophoresis on silver-stained denaturing acrylamide gels (7\%) (Creste et al., 2001). Molecular size of the fragments was estimated using a 10-bp ladder (Invitrogen).

Since C. longa is considered to be a triploid species, banding patterns of each genotype were represented in a binary matrix, coded according to the absence or presence of bands and analyzed as dominant markers. Shannon-Wiener indexes were calculated for each group of genotypes, according to the region where the accession was collected. Analysis of genetic structure was performed using AMOVA to estimate the variance between and within groups of accessions (Excoffier et al., 1992) using the Arlequin v.2.0 software (Schneider et al., 2000). AMOVA provides an estimate, $\phi_{\mathrm{ST}}$ of group differentiation, which is an analog to the $F_{\mathrm{ST}}$ statistic when the degree of relatedness among the genetic variants is evaluated. For this analysis, molecular genetic diversity was hierarchized into two different schemes. First, only Brazilian accessions were considered by dividing them into five subgroups according to their state of origin. In the second analysis, two more groups were added, comprising the genotypes from India and Puerto Rico. 
M.S. Sigrist et al.

422

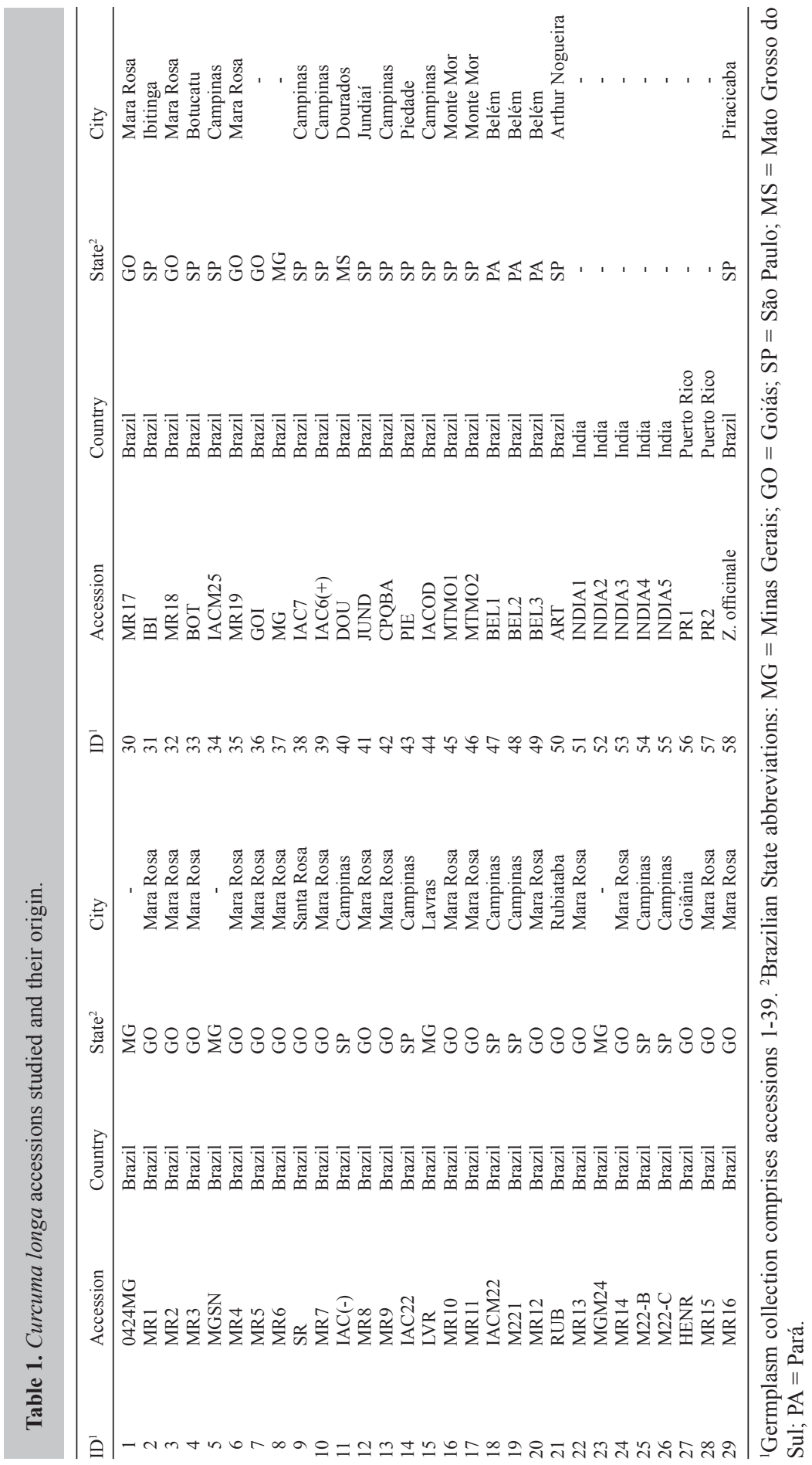


To evaluate the genetic structure of the collection without a priori hierarchy, the Bayesian approach proposed by Pritchard et al. (2000) was implemented using the Structure software. The latest version of the software (2.3.3) includes the algorithm of Falush et al. (2007), which can handle genotypic ambiguity (where it is not possible to identify the exact genotypes in heterozygotes, e.g., triploid individuals displaying two alleles). As we observed individuals with a maximum of three bands in all loci, we ran Structure considering all the individuals as triploids. Following the user's guide for the software, the three rows of each individual at a given locus (representing the three alleles) were filled in with the alleles observed (one, two or three alleles). The integer for missing data (-9) was used to complete the infile, and the option RECESSIVEALLELES was set to 1 . The program thus considers that the three alleles are codominant to each other, and that there is genotypic ambiguity. In this way, we incorporated all alleles observed in the sample to evaluate the germplasm's genetic structure. Number of clusters was defined from $K=1$ to $K=10$, and 10 runs of each K were performed with 200,000 burn-in period and 500,000 MCMC (Markov Chain Monte Carlo). The optimal number of clusters was estimated using $\Delta \mathrm{K}$ values, following Evanno et al. (2005).

Our results from these previous analyses were then compared to the dendrogram of genetic divergence, obtained using pair-wise similarity coefficients (Sigrist et al., 2009). The NTSYS-PC version 1.70 software (Rohlf, 1989) was used to calculate the dendrogram's cophenetic value, in order to check the goodness of fit between the cluster analysis and the matrix on which it was based. For discussion purposes, we used the mean value of the similarity matrix as a threshold to determine the main groups of accessions.

\section{RESULTS}

All SSR markers used in the genetic analysis were polymorphic, with banding patterns ranging from one to a maximum of three alleles per individual in all loci. The mean number of alleles per locus was 6.71. Shannon-Weiner genetic diversity indexes for each group of genotypes are summarized in Table 2. The highest index was found for the group of genotypes from São Paulo State $(\mathrm{I}=0.316)$ and the lowest for genotypes from Minas Gerais State $(\mathrm{I}=0.017)$. The major turmeric producing region in Brazil, Goiás State, also had a low index, even though this group comprised the largest number of accessions analyzed.

\section{Table 2. Shannon-Weiner indexes for each group of Curcuma longa accessions studied.}

\begin{tabular}{llcr}
\hline Country & State & Number of accessions & Shannon-Weiner index \\
\hline Brazil & Goiás & 24 & 0.033 \\
& São Paulo & 18 & 0.316 \\
& Minas Gerais & 4 & 0.017 \\
& Pará & 3 & 0.202 \\
Puerto Rico & Mato Grosso do Sul & 1 & - \\
India & - & 2 & 0.025 \\
Total & - & 57 & 0.075 \\
\hline
\end{tabular}


To test the structure of genetic variation based on the origin of the genotype, the AMOVA procedure comprising only Brazilian genotypes indicated that the majority of the total genetic diversity $(75.29 \%)$ was attributed to differences between genotypes within Brazilian states (Table 3$)$. However, a significant $\phi_{\mathrm{ST}}$ value $(0.247, \mathrm{P}<0.01)$ also suggests the existence of differentiation among genotypes from different states. However, when accessions from India and Puerto Rico were included, most of the genetic variation was due to differences between groups $(0.634, \mathrm{P}<0.05)$, indicating that major differences were found between countries. Nevertheless, significant differences were still found between $(0.09, \mathrm{P}<$ $0.01)$ and within $(0.27, \mathrm{P}<0.01)$ the Brazilian groups of accessions (Table 4).

Table 3. Analysis of molecular variance (AMOVA) based on 17 SSR markers observed from 50 Brazilian accessions of Curcuma longa.

\begin{tabular}{lrccc}
\hline Source of variation & d.f. & SSD & \% of variance & $\boldsymbol{\phi}_{\text {statistics }}$ \\
\hline Between states & 4 & 104.22 & 24.71 & $\boldsymbol{\phi}_{\text {ST }}=0.247$ \\
Within states & 45 & 327.24 & 75.29 & $1-\boldsymbol{\phi}_{\mathrm{ST}}$ \\
Total & 49 & 431.46 & & $<0.01$ \\
\end{tabular}

d.f. $=$ degrees of freedom; $\mathrm{SSD}=$ sum of squared deviations.

Table 4. Analysis of molecular variance (AMOVA) including Curcuma longa accessions from Brazil (50), India (5) and Puerto Rico (2).

\begin{tabular}{|c|c|c|c|c|c|}
\hline Source of variation & d.f. & SSD & $\%$ of variance & $\phi$ statistics & $\mathrm{P}$ \\
\hline Between countries & 2 & 239.80 & 63.42 & $\phi_{1}=0.634$ & $<0.05$ \\
\hline Between states within countries & 4 & 104.22 & 9.52 & $\phi_{\mathrm{SC}}^{\mathrm{CT}}=0.095$ & $<0.01$ \\
\hline Within states & 50 & 345.54 & 27.05 & $1-\phi_{\mathrm{ST}}^{\mathrm{SC}}=0.270$ & $<0.01$ \\
\hline Total & 56 & 689.56 & & & \\
\hline
\end{tabular}

d.f. $=$ degrees of freedom; SSD $=$ sum of squared deviations.

To test the genetic structure of the germplasm collection without a priori hierarchy, a Bayesian clustering method (Structure) was tested to infer the optimal number of groups. According to the $\Delta \mathrm{K}$ values, the highest log likelihood scores were found when the number of groups was set at two. Bayesian admixture analysis at $\mathrm{K}=2$ (Figure 1) indicated the assemblage of most individuals within one group, comprising $84 \%$ of the Brazilian accessions (considering $\mathrm{Q}>0.8$ ). Some genotypes from Brazil were clustered in a separate group, composed of the following genotypes IAC(-), IAC6(+), IACOD, JUND, PIE, MTMO2, MTMO1, BEL1, and BEL2. In addition to these accessions, the samples from Puerto Rico and India were also included in this group. These results using the Bayesian clustering method were similar to the cluster analysis using the UPGMA method (Figure 2). However, considering a similarity coefficient less than 0.59 in the later analysis, it was possible to discriminate five main groups of accessions instead of two. In this case, one of the groups obtained in Structure analysis was divided into four smaller groups, comprising: Indian accessions (II), MTMO1 and BEL1 (III), some genotypes from São Paulo State (IV), and accessions from Puerto Rico (V). As previously observed, the majority of Brazilian genotypes clustered within a large, highly similar group (I). It is interesting to note that the division in five groups displays a better agreement with one of the hierarchies tested in AMOVA, which divides the genotypes according to the countries where they were collected. 


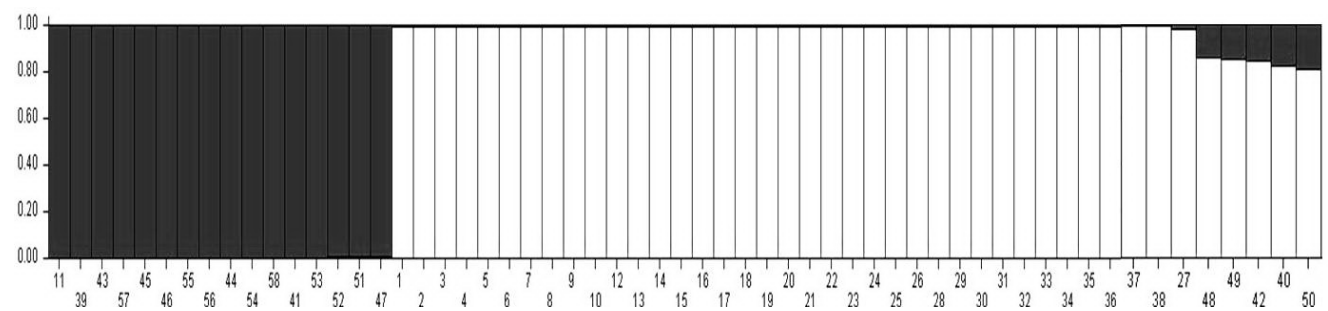

Figure 1. Clustering of individuals by Structure at $\mathrm{K}=2$. Individuals are represented by vertical bars. Same colors in different individuals indicate that they belong to the same cluster. Different colors in the same individual indicate the percentage of the genome shared with each cluster, according to the admixture proportions. Numbers refer to the individuals described in Table 1.

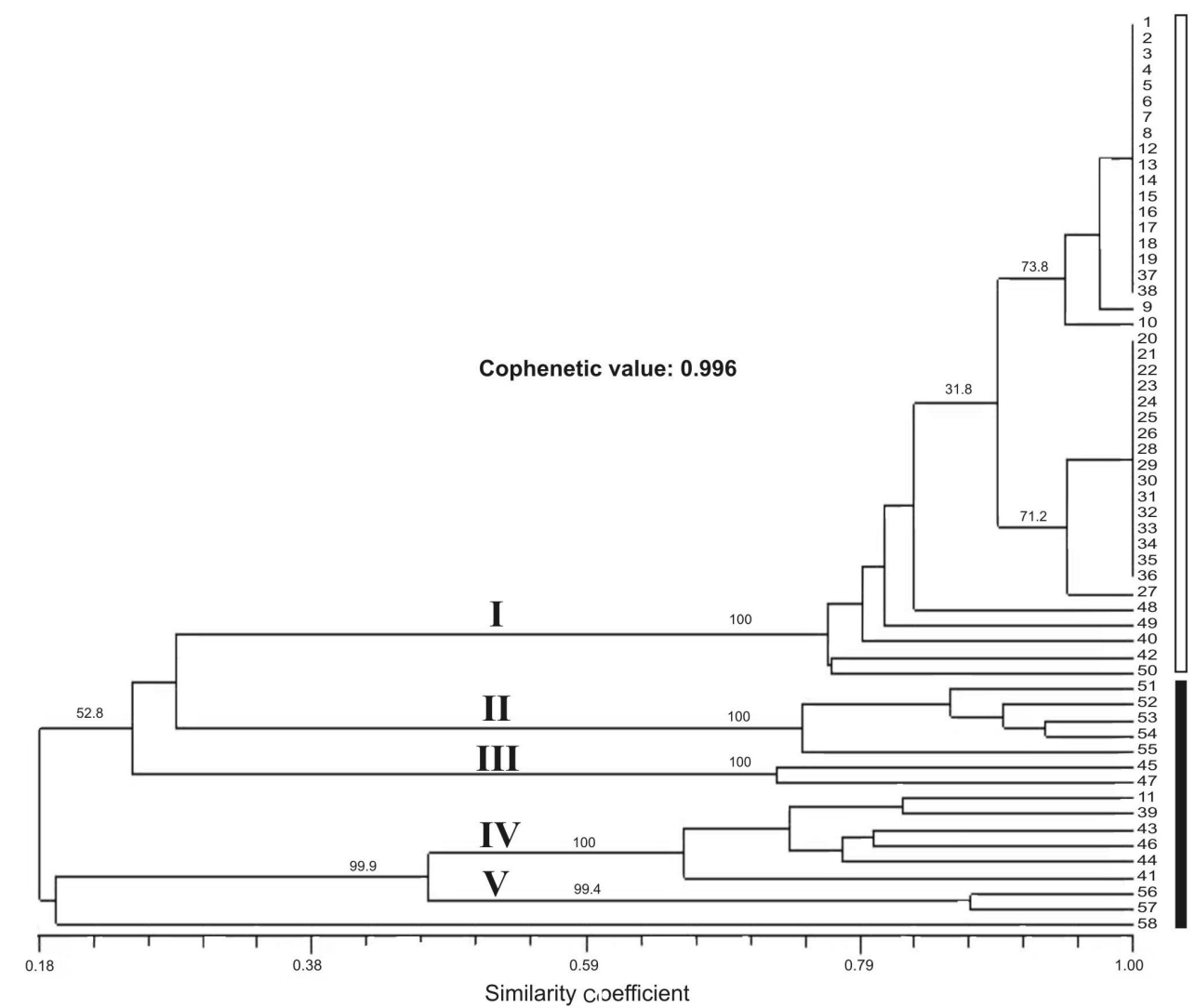

Figure 2. Dendrogram showing the genetic relationships among turmeric accessions based on Jaccard's similarity coefficient using SSR markers (UPGMA) (modified from Sigrist et al., 2009). Roman numerals indicate the five main groups of accessions, considering a similarity coefficient less than 0.59 . Black and white bars on the right compare the main groups obtained in Structure analysis. 


\section{DISCUSSION}

The first outcome of the present study is the corroboration of the previous hypothesis regarding C. longa as a triploid species (Islam, 2004; Sasikumar, 2005; Ravindran et al., 2007). All microsatellite markers amplified a maximum of three alleles per individual in all C. longa samples tested, a pattern that was also verified by Siju et al. (2010). According to Ravindran et al. (2007), the basic chromosome number in C. longa is $\mathrm{x}=21$; however, some aneuploid genotypes $(2 \mathrm{n}=3 \mathrm{x}=62$ or 64$)$ have been reported (Joseph et al., 1999; Sasikumar, 2005). Is has been assumed that the triploid condition may have arisen from natural crosses between diploid and tetraploid ancestors, a condition that was maintained through vegetative propagation. Recently, Skornickova et al. (2007) proposed that the basic chromosome number for the genus Curcuma should be considered $\mathrm{x}=7$, and therefore, $C$. longa should be regarded as a nonaploid species. However, SSR data presented here do not support this proposal.

Overall genetic variability for the groups studied, represented by Shannon-Weiner indexes, was relatively low, although it was still higher than that found in other studies evaluating turmeric accessions (Islam, 2004). It is important to consider that this index depends on the number of accessions analyzed in each group, and thus, a higher index is expected for groups with more accessions. The highest index was shown by genotypes from the São Paulo State followed by those from Pará State, which was represented by only a few accessions. On the other hand, genotypes from Goiás State displayed a low variability, despite the fact that most accessions evaluated were from this State, which is the main producing region in Brazil.

Previously, Pinheiro et al. (2003) and Cintra et al. (2005) reported that the genetic variability of turmeric from Brazil is quite low. Even though their studies involved fewer accessions than the present investigation, all results suggest that most of the genetic variation occurs within the states where the crop is cultivated. Indeed, this is true only if we consider São Paulo and Pará States, which contain highly divergent genotypes. Taking into account the result of both Structure and cluster analyses, it is possible to see that most accessions within Goiás and Minas Gerais States are highly similar, some of which could even be regarded as the same genotype.

This lack of polymorphism is probably due to the introduction of a few genotypes in Brazil, which were, since then, vegetatively propagated. Moreover, the accessions from Goiás State were obtained from small farmers within a few square kilometers, and the exchange of planting materials might have spread the same clones over the area. Although the genotypes planted in São Paulo are probably originally from Goiás, turmeric production is less concentrated and the selection of distinct sports during propagation has already been performed in research institutes.

Among these materials from São Paulo, IAC(-) and IAC6(+) have already been previously reported as the most divergent turmeric genotypes in Brazil, even at the phenotypic level (Cintra et al., 2005). These genotypes are the result of germplasm selection with low and high levels of curcumin (color pigment). Considering that high level of curcumin content is a major requirement by food industries and the divergence level of accession IAC $(+)$, it should be a promising material for genetic improvement of the crop.

Since the turmeric collection has been maintained in vivo for many years, it is im- 
portant to consider the costs and benefits of maintaining a large number of highly similar materials. One possible way to overcome this problem, without losing potentially useful alleles, is to make a mixed sample comprising highly related accessions (Gilbert et al., 1999). In the case of future needs, breeders would still be able to identify and select useful variations within each sample, with less management expenses. Based on the groups presented here, 3-6 pools of genotypes may be sufficient to represent the genetic variability within and between accessions of the turmeric collection. However, other levels of variability are still needed to be tested, such as the chemical profiles and the phenotypic responses under field conditions.

Meanwhile, another requirement is to broaden the collection's genetic base, which may be achieved through different approaches. One possibility is the introduction of new materials, especially from countries where greater genetic variability occurs. Studies screening germplasm collections using phenotypic traits have revealed large genetic divergence among cultivars from Southeast Asia, a region that should be an important source of genetic variation for turmeric improvement worldwide (Singh et al., 2003; Sasikumar, 2005; Chaudhary et al., 2006). Besides, another approach that has been recently developed for turmeric is the use of tissue culture techniques, including the induction of genetically distinct shoots, protoplast fusion and genetic transformation via particle bombardment (Salvi et al., 2002; Shirgurkar et al., 2006). Also worth mentioning is the possibility of obtaining viable seeds, which still needs to be investigated under Brazilian conditions. As a vegetatively propagated crop, turmeric is highly heterozygous, and hybridization between some divergent genotypes, even among those found in Brazil, could broaden the genetic base for selection.

The use of SSR markers has been demonstrated to be a powerful tool to define how turmeric genetic diversity is structured in Brazil, leading to a better management of the germplasm bank and also to promote the use of these accessions in further breeding programs. The results presented here are the first step towards a better knowledge of the germplasm available in Brazil and can help to guide future studies of the crop.

\section{ACKNOWLEDGMENTS}

Research supported by Fundação de Amparo à Pesquisa do Estado de São Paulo (FAPESP) (project \#07/02895-4). The authors are thankful to Dr. David D. Ellis, Dr. Brian M. Irish and Dr. S. Sandhu for providing DNA samples from Puerto Rico and India.

\section{REFERENCES}

Antunes LMG and Araújo MCP (2000). Mutagenicidade e antimutagenicidade dos principais corantes para alimentos. Rev. Nutr. 13: 81-88.

Araujo CC and Leon LL (2001). Biological activities of Curcuma longa L. Mem. Inst. Oswaldo Cruz 96: 723-728.

Cecílio-Filho AB, Souza RJ, Braz LT and Tavares M (2000). Cúrcuma: planta medicinal, condimentar e de outros usos potenciais. Cienc. Rural 30: 171-175.

Chandra R, Desai AR, Govind S and Gupta PN (1997). Metroglyph analysis in turmeric (Curcuma longa L.) germplasm in India. Sci. Hortic. 70: 211-222.

Chaudhary AS, Sacham SK and Singh RL (2006). Studies on varietal performance of turmeric (Curcuma longa L.). Indian J. Crop Sci. 1: 189-190.

Cintra MMDF, Pinheiro JB and Sibov ST (2005). Genetic divergence among Curcuma longa L. accessions. Crop Breed. Appl. Biotechnol. 5: 410-417. 
Creste S, Tulmann-Neto A and Figueira A (2001). Detection of single sequence repeat polymorphims in denaturing polyacrylamide sequencing gels by silver staining. Plant Mol. Biol. Rep. 19: 299-306.

Doyle JJ and Doyle J (1987). A rapid DNA isolation procedure for small quantities of fresh leaf tissue. Phytochem. Bull. 19: 11-15.

Evanno G, Regnaut S and Goudet J (2005). Detecting the number of clusters of individuals using the software STRUCTURE: a simulation study. Mol. Ecol. 14: 2611-2620.

Excoffier L, Smouse PE and Quattro JM (1992). Analysis of molecular variance inferred from metric distances among DNA haplotypes: application to human mitochondrial DNA restriction data. Genetics 131: 479-491.

Falush D, Stephens M and Pritchard JK (2007). Inference of population structure using multilocus genotype data: dominant markers and null alleles. Mol. Ecol. Notes 7: 574-578.

Ferreira ME, Moretzsohn MC and Buso GSC (2007). Fundamentos de Caracterização Molecular de Germoplasma Vegetal. In: Recursos Genéticos Vegetais (Nass LL, ed.). Embrapa, Brasília, 858.

Gilbert JE, Lewis RV, Wilkinson MJ and Caligari PDS (1999). Developing an appropriate strategy to assess genetic variability in plant germplasm collections. Theor. Appl. Genet. 98: 1125-1131.

Islam A (2004). Genetic diversity of the genus Curcuma in Bangladesh and further biotechnological approaches for in vitro regeneration and long-term conservation of $C$. longa germplasm. $\mathrm{PhD}$ thesis, University of Hannover, Hannover.

Joseph R, Joseph T and Jose J (1999). Karyomorphological studies in the genus Curcuma Linn. Cytologia 64: 313-317.

Lynrah PG, Barua PK and Chakrabarty BK (1998). Pattern of genetic variability in a collection of turmeric (Curcuma spp) genotypes. Indian J. Genet. 58: 201-207.

May A, Cecilio-Filho AB, Cavarianni RL and Barbosa JC (2005). Turmeric (Curcuma longa L.) development and productivity in function at nitrogen and potassium doses. Rev. Bras. Plant Med. 7: 73-78.

Meenakshi N and Sulikeri GS (2003). Effect of different planting materials on growth, yield and productivity of turmeric (Curcuma longa L.). Inter. J. Trop. Agric. 21: 37-44.

Nass LL (2001). Utilização de Recursos Genéticos Vegetais no Melhoramento. In: Recursos Genéticos e Melhoramento - Plantas (Nass LL, Valois ACC, Melo IS and Valadares-Inglis MC, eds.). Fundação MT, Rondonópolis, 29-56.

Pinheiro JB, Zucchi MI, Teles FL and Azara NA (2003). Diversidade genética molecular em acessos de açafrão utilizando marcadores RAPD. Acta Sci. Agron. 25: 195-199.

Powell W, Morgante M, Chaz A, Hanafey M, et al. (1996). The comparison of RFLP, RAPD, AFLP and SSR (microsatellite) markers for germplasm analysis. Mol. Breed. 2: 225-238.

Pritchard JK, Stephens M and Donnelly P (2000). Inference of population structure using multilocus genotype data. Genetics 155: 945-959.

Ravindran PN, Babu KN and Sivaranan K (2007). Turmeric: The Genus Curcuma. Medicinal and Aromatic Plants Industrial Profiles. CRC Press, Boca Raton.

Rohlf F (1989). NTSYS-PC: Numerical Taxonomy and Multivariate Analysis System. Exeter Publisher, New York.

Salvi ND, George L and Eapen S (2002). Micropropagation and field evaluation of micropropagated plants of turmeric. Plant Cell. Tissue Organ Cult. 68: 143-151.

Sasikumar B (2005). Genetic resources of Curcuma: diversity, characterization and utilization. Plant Genet. Res. 3: 230251.

Sasikumar B, Johnson KG, Zachariah TJ, Ratnambal MJ, et al. (1996). IISR Prabha and IISR Prathibha - two new high yielding and high quality turmeric (Curcuma longa L.) varieties. J. Spices Aromatic Crops 5: 41-48.

Schneider S, Roessli D and Excoffier L (2000). Arlequin: A Software for Population Data Analysis. University of Geneva, Geneva, 111.

Shirgurkar MV, Naik VB, von Arnold S, Nadgauda RS, et al. (2006). An efficient protocol for genetic transformation and shoot regeneration of turmeric (Curcuma longa L.) via particle bombardment. Plant Cell. Rep. 25: 112-116.

Sigrist MS, Pinheiro JB, Azevedo-Filho JA, Colombo CA, et al. (2009). Development and characterization of microsatellite markers for turmeric (Curcuma longa L.). Plant Breed. 129: 570-573.

Siju S, Dhanya K, Syamkumar S, Sasikumar B, et al. (2010). Development, characterization and cross species amplification of polymorphic microsatellite markers from expressed sequence tags of turmeric (Curcuma longa L.). Mol. Biotechnol. 44: 140-147.

Singh Y, Mittal P and Katoch V (2003). Genetic variability and heritability in turmeric (Curcuma longa L.). Himachal J. Agric. Res. 29: 31-34.

Skornickova JL, Sida O, Jarolimova V, Sabu M, et al. (2007). Chromosome numbers and genome size variation in Indian species of Curcuma (Zingiberaceae). Ann. Bot. 100: 505-526. 